\title{
The influence of female oviposition strategy on sibling cannibalism in the ladybird beetle Harmonia axyridis (Coleoptera: Coccinellidae)
}

\author{
NAOYA OSAWA \\ Laboratory of Forest Ecology, Graduate School of Agriculture, Kyoto University, Kyoto, 606-8502 Japan; \\ e-mail: osawa@kais.kyoto-u.ac.jp
}

Key words. Coccinellidae, egg fertility, Harmonia axyridis, oviposition strategy, sibling cannibalism

\begin{abstract}
I hypothesized that sibling cannibalism is one of maternal investment in that a female controls sibling cannibalism. To test the hypothesis, I conducted a laboratory experiment and field observations to investigate sibling cannibalism in relation to cluster size and cluster site in the ladybird beetle, Harmonia axyridis Pallas. In the laboratory experiment, cluster size significantly affected the number of cannibalized eggs per cluster $\left(R^{2}=0.516\right)$, while cluster size was significantly affected by the oviposition interval. Furthermore, there was a marginally significant positive relationship between cluster size and the percentage of sibling cannibalism per cluster. In the field, cluster size and the direct distance from a cluster site to an aphid colony (an indicator of intensity of nonsibling cannibalism) significantly affected the number of cannibalized eggs per cluster $\left(\mathrm{R}^{2}=0.472\right)$. Furthermore, there was a significant positive relationship between the direct distance from a cluster to the nearest aphid colony and cluster size. However, there was not a significant relationship between the distance and the percentage of sibling cannibalism. These results may be caused by the weakness of the female's power to control sibling cannibalism. Thus, a female $H$. axyridis controls cluster size through the intensity of non-sibling cannibalism, which may be one of oviposition strategies in this species.
\end{abstract}

\section{INTRODUCTION}

Some of the most important elements in insect reproductive tactics relate to how many eggs are laid in a patch, how egg and cluster sizes are determined, and how patch quality is evaluated (e.g., Parker \& Courtney, 1984; Godfray, 1987). Many aphidophagous coccinellids lay their eggs in clusters when aphid densities are high (Hodek \& Honek, 1996). Sibling cannibalism is often observed among larvae resulting from egg clusters of aphidophagous ladybird beetles; cannibals consume never-hatched eggs as well as fertile eggs that have delayed hatching (Osawa, 1989; Stevens, 1992; Hodek \& Honek, 1996. Sibling cannibalism can be influenced by parental manipulation (Alexander, 1974; Polis, 1981), suggesting that it results from a kind of maternal investment in the offspring. Accordingly, the selection of suitable cluster sites and the manipulation of sibling cannibalism may be important components of the reproductive tactics of aphidophagous ladybird beetles.

Field and laboratory experiments indicate that ladybird beetles tend to lay eggs where there are sufficient numbers of aphids to ensure the survival of first-instar beetle larvae (Dixon, 1959; Wratten, 1973; Honek, 1978; Mills, 1982). Cues used to find a cluster site include the presence of aphids (Evans \& Dixon, 1986), conspecific larvae (Hemptinne et al., 1992), and pheromones (Doumbia et al., 1998). Furthermore, the timing of oviposition is also critical to guarantee sufficient food for the offspring; females often lay eggs well before aphid densities peak (Hemptinne et al., 1992; Osawa, 2000). Beyond these factors, however, how females determine the suitability of oviposition sites and what factors affect sibling canni- balism are not well documented, especially under field conditions.

The adaptive significance of sibling cannibalism at the population level is mainly considered to be its selfregulatory effect on populations (Fox, 1975; Polis, 1980, 1981). Density is usually a key factor in the population dynamics of cannibalism (Dong \& Polis, 1992). In a natural population of Harmonia axyridis Pallas, sibling cannibalism occurred in more than $90 \%$ of all clusters (Osawa, 1989), and approximately 30\% of eggs were killed by sibling cannibalism (Osawa, 1993). Interestingly, sibling cannibalism in this species is density-independent, suggesting that sibling cannibalism in $H$. axyridis is not a self-regulatory mechanism, but a "hedged bet" in the population (Osawa, 1993).

In one study of $H$. axyridis, $35 \%$ of all eggs were cannibalized, of which $70 \%$ were never-hatched eggs, and $30 \%$ were fertile eggs with delayed hatching (Osawa, 1993). In social insects, never-hatched eggs are considered to play an adaptively significant role as nurse or trophic eggs, because they do not develop and therefore have no reproductive value (Polis, 1981). In earlier laboratory experiments with coccinellids, the existence of embryos has been used as the criterion to determine the fertility of eggs (Brown, 1972; Osawa, 1992). However, the mechanisms involved in the production of never-hatched eggs are not yet fully understood: it is not clear whether the eggs are infertile or die during early development. Recently, it has been suggested that one important factor resulting in fertile but never-hatched eggs may be the presence of male-killing microorganisms (e.g., Hurst \& Majerus, 1993). However, it is still not clear whether all the never-hatched eggs are caused by "male-killers". 
When a cannibal eats fertile eggs that have delayed hatching, the adaptive significance of sibling cannibalism may be explained by kin selection (Hamilton, 1964a, 1964b): Sibling cannibalism is adaptive for the cannibal and the cannibalized in periods of low aphid densities (Osawa, 1992). Sibling cannibalism is not maladaptive for the mother: She attains almost equal fitness regardless of the intensity of sibling cannibalism (Osawa, 1992). In ladybird beetles, newly hatched larvae cannot easily capture aphids (Dixon, 1959; Kawai, 1978). A H. axyridis female lays an egg cluster apart from an aphid colony, with the result that food shortage for a newly hatched larva is severe (Osawa, 1989). In case of sibling cannibalism, therefore never-hatched eggs and eggs with delayed hatching play important roles as part of maternal investment, regardless of their fertility. The factors affecting the selection of cluster sites and the occurrence of sibling cannibalism within a cluster need to be investigated, because the site selection determines the access of offspring to aphids and may, therefore be related to the incidence of sibling cannibalism.

In this study, I hypothesized that sibling cannibalism is part of maternal investment and is female-controlled. To test this hypothesis, I examined factors affecting sibling cannibalism, cluster size, and cluster site selection, through a combination of a laboratory experiment and field observations.

\section{MATERIALS AND METHODS}

\section{A laboratory experiment}

The ladybird beetle Harmonia axyridis Pallas has a wide distribution throughout northeast Asia (Sasaji, 1971) and is one of the most common aphidophagous coccinellids in Japan. The laboratory experiment was conducted for 17 days, from 24 April to 13 May, 1990. Fifteen $H$. axyridis adults (10 females and 5 males) were collected at the Botanical Garden of Kyoto University $\left(35^{\circ} 02^{\prime} \mathrm{N} 135^{\circ} 47^{\prime} \mathrm{W}\right)$ and were used in the following analysis. To evaluate potential effects of mating on the oviposition ability of females, they were categorized into two types: females with males $(\mathrm{n}=5)$ and females without males $(\mathrm{n}=5)$. I then compared the oviposition ability of the two types of females. The 10 females ( 5 with males, 5 without) were held individually in plastic Petri dishes ( $7 \mathrm{~cm}$ wide, $2 \mathrm{~cm}$ high). They were reared individually with a surplus of aphids, Aphis spiraecola Patch (c. 500 individuals), and a shoot of Spiraea thunbergii (Rosaceae), which was changed daily. The following laboratory conditions were maintained: $25^{\circ} \mathrm{C}, 16 \mathrm{~L}: 8 \mathrm{D}$, ca. $70 \%$ relative humidity. I checked the Petri dishes daily, counted all eggs that were laid, and recorded the number of eggs per cluster and the female code. After removing the beetles, each egg cluster was kept individually in a Petri dish labelled with the female code and the oviposition date. Eggs were held under the same laboratory conditions and checked daily. Twenty-four hours after the eggs hatched, I recorded the number of larvae. Thereafter, missing eggs were regarded as cannibalized eggs. Oviposition interval (the number of days since the previous oviposition) was also calculated for each cluster. In total, 104 egg clusters were obtained and used for the analysis.

\section{Field experiments}

To examine factors affecting the oviposition of $H$. axyridis females, I conducted a field experiment at the Botanical Garden of Kyoto University. In 1987 and 1988, all clusters found on three Prunus persica trees (2-4 $\mathrm{m}$ in height) that were colonized by two species of aphids (Myzus varians Davidson and Hyalopterus pruni Geoffroy) were marked and individually identified with numbered red vinyl tape. I determined the cluster code and recorded the date, cluster size, and the ecological conditions for the cluster sites (i.e. location of the cluster on or below the surface of a leaf or other location; the occurrence of aphid colonies on the same shoot $(+/-)$; the occurrence of aphid colonies on the same twig $(+/-)$; the occurrence of clusters of $H$. axyridis on the same shoot $(+/-)$; and the "direct" and "route" distances from a cluster site to the nearest aphid colony). Any or all of these factors may be important for females to determine a suitable cluster site from the viewpoint of the intensity of egg predation and food availability for the offspring. I wrote the cluster code and the date of the first finding of the cluster on the vinyl tape. When I found an egg cluster, I measured the straight-line distance from the cluster site to several aphid colonies near the cluster site; I determined the shortest distance from the cluster site to the nearest aphid colony (i.e., the "direct" distance). I also measured the distance required for a newly hatched larva to travel from a cluster site to the nearest aphid colony via a leaf, shoot, or twig (i.e., the "route" distance). H. axyridis females lay eggs slightly away from aphid colonies, which may reduce the intensity of non-sibling cannibalism (Osawa, 1989). However, the selection of distant oviposition sites may cause severe food shortages for the offspring, because newly hatched larvae are relatively immobile and cannot easily capture aphids (Dixon, 1959; Kawai, 1978). The females often migrate from the oviposition site by flight after they lay eggs, whereas the newly-hatched larvae stay for about one day at a cluster site in a group and they leave from there in all directions by crawling along leaves, shoots, and twigs, subsequently reaching an aphid colony. Therefore, the direct distance from a cluster site to the nearest aphid colony may be an indicator of maternal investment that is reflected in the intensity of non-sibling cannibalism (i.e. the greater the distance, the lower levels of non-sibling cannibalism) and, route distance an indicator of maternal investment that is reflected in the food availability for the offspring (i.e. the greater the distance, the less readily available the prey), although there is a positive correlation between these two measures. In the field, non-siblings (mainly younger larvae) usually cannibalize only unhatched eggs; they do not eat newly hatched larvae that stay at a cluster site. Therefore, non-sibling cannibalism occurs first, and thereafter additionally sibling cannibalism supervenes. A part of the cluster was cannibalized when one non-sibling larva cannibalized a cluster, while all the eggs in the cluster were cannibalized when two or more non-sibling larvae cannibalized a cluster. When non-sibling cannibalism occurred, the non-sibling cannibal was much larger than the sibling larvae or the instars of the non-sibling cannibal were usually different from that of the sibling larva. Furthermore, the condition of the cannibalized egg in sibling cannibalism was different from that in non-sibling cannibalism: A part of the egg was usually left in non-sibling cannibalism, whereas the entire egg was eaten in sibling cannibalism. Accordingly, the occurrence of sibling and non-sibling cannibalism can be distinguished even in the field. I checked marked clusters for the occurrence of non-sibling cannibalism and the date of hatching on a daily basis. I recorded the number of hatchlings per cluster when the eggs hatched. In total, 151 clusters were recorded over the two years. To detect the effect of sibling cannibalism on a cluster, 50 clusters that had been damaged by non-sibling cannibalism were eliminated, and the remaining 101 clusters were used in the following analysis. The combined field data from 1987 and 1988 were used for the analysis of the field experiment. 

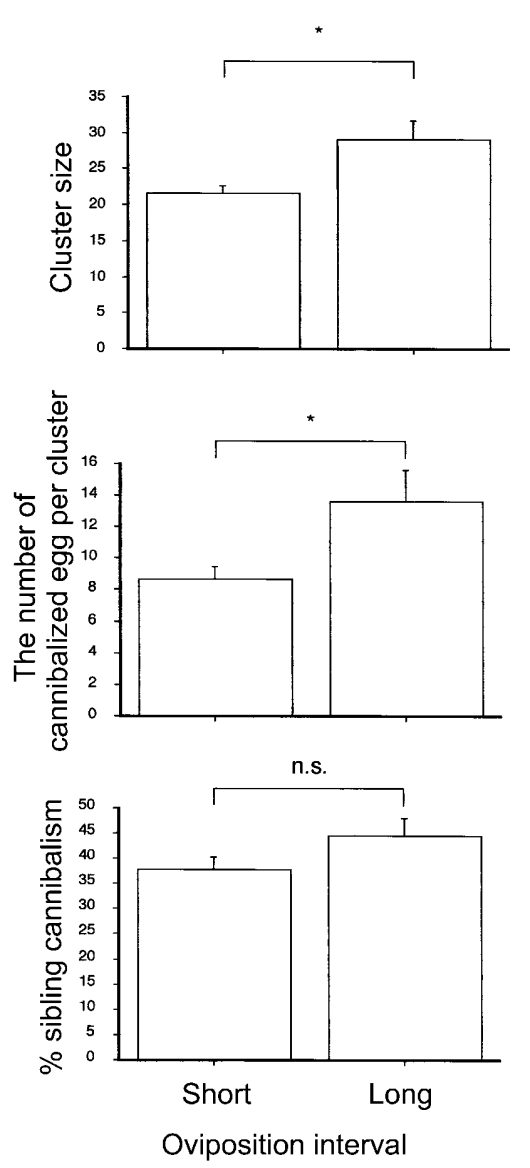

Fig. 1. The comparison of cluster size, the number of cannibalized eggs per cluster, and the percentage of sibling cannibalism per cluster between short ( $=1$ day) and long ( $\geq 2$ days) oviposition interval. An asterisks $(*)$ indicates significance of the $P<0.05$ level, n.s. indicates non-significance. Vertical lines indicate $\pm 1 \times$ standard errors.

\section{Data analysis}

To compare characteristics of egg clusters between a female with and without a male, $t$-test was performed. From the preliminary analysis of the laboratory data, the identity of female (= female code) was not a significant factor affecting the number of cannibalized eggs per cluster, and cluster size (One-way ANOVA: $F_{9,94}=1.511, p=0.1554, F_{9,94}=1.254, p=$ 0.2723 , respectively). Accordingly, I performed a two-way ANOVA after stepwise removal of non-significant terms to analyze the number of cannibalized eggs per cluster and cluster size in the laboratory data. Female code was a significant factor affecting the percentage of sibling cannibalism per cluster (One-way ANOVA: $F_{9,94}=3.085, p=0.0028$ ), suggesting that the clusters laid by one female could not be treated as inde- pendent units. Accordingly, I used a two-level nested ANOVA to analyze the relationship between the percentage of sibling cannibalism and cluster size. To analyze the effect of oviposition interval on cluster size, the number of cannibalized eggs per cluster, and the percentage sibling cannibalism per cluster, the oviposition interval was divided into two categories: short $(=1$ day) and long ( $\geq 2$ days). Thereafter, the comparison was made using Tukey-Kramer HSD test. A four-way ANOVA was used to analyze the field data because different females may lay each cluster, judging from their short stays at each habitat (Osawa, 2000). The percentage data of sibling cannibalism were arcsine transformed before linear regression analysis because the original percentage data in my experiment fall below $30 \%$ and over $70 \%$ (Sokal \& Rohlf, 1980). For all of these statistical analyses, I used JMP Discovery Software (SAS, 2000).

\section{RESULTS}

\section{A laboratory experiment}

There were no significant differences in cluster size, cluster egg total, number of eggs cannibalized per cluster, percentage sibling cannibalism per cluster, and oviposition interval between a female with and without a male (Table 1). Among the factors that might have affected how many eggs were cannibalized per cluster, the effect of cluster size was significant when I eliminated other factors (i.e., oviposition interval, interaction between cluster size and oviposition interval, and interaction between oviposition interval and mating) from the model $\left(p<0.0001 ; F_{3,100}=35.606, \mathrm{R}^{2}=0.516\right.$ and $p<0.0001$, for the model; Table 2). The occurrence of mating and the interaction between cluster size and the occurrence of mating were not significant factors affecting the number of cannibalized eggs per cluster $(p=0.1256, p=0.0993$, respectively; Table 2 ). The oviposition interval significantly affected the cluster size ( $p=0.0014$; Table 3 ), whereas the effect of the interaction with the occurrence of mating was not significant ( $p=0.1775$; Table 3 ). Furthermore, the effect of occurrence of mating on the cluster size was only marginally significant $(p=0.0639$; Table 3). There was also a marginally significant relationship between cluster size and the percentage of sibling cannibalism per cluster $\left(p=0.0525 ; F_{19,84}=2.619, \mathrm{R}^{2}=\right.$ 0.372 and $p=0.0014$ for the model; Table 4). Cluster size and the number of cannibalized eggs per cluster in long oviposition period were significantly larger than those in short one ( $p<0.05$ and $p<0.05$, respectively: Fig. 1). However, no significant difference was observed in the percentage sibling cannibalism per cluster between short and long oviposition intervals ( $p>0.05$ : Fig. 1$)$.

TABLE 1. Comparison between females with males and females without males in the laboratory experiment.

\begin{tabular}{lccc}
\hline & $\begin{array}{c}\text { a female with a male } \\
\text { (mean } \pm \text { S.E. })\end{array}$ & $\begin{array}{c}\text { a female without a male } \\
\text { (mean } \pm \text { S.E.) }\end{array}$ & $P^{*}$ \\
\hline Cluster size & $25.103 \pm 1.660$ & $22.522 \pm 1.865$ & 0.3036 \\
Cluster egg total & $291.200 \pm 35.470$ & $207.200 \pm 35.470$ & 0.1326 \\
No. of eggs cannibalized per cluster & $11.724 \pm 1.210$ & $8.457 \pm 1.359$ & 0.0754 \\
\% sibling cannnibalism per cluster & $42.077 \pm 2.625$ & $37.198 \pm 2.948$ & 0.2193 \\
Oviposition interval & $1.466 \pm 0.151$ & $1.844 \pm 0.172$ & 0.1013 \\
\hline
\end{tabular}

$* t$-test 


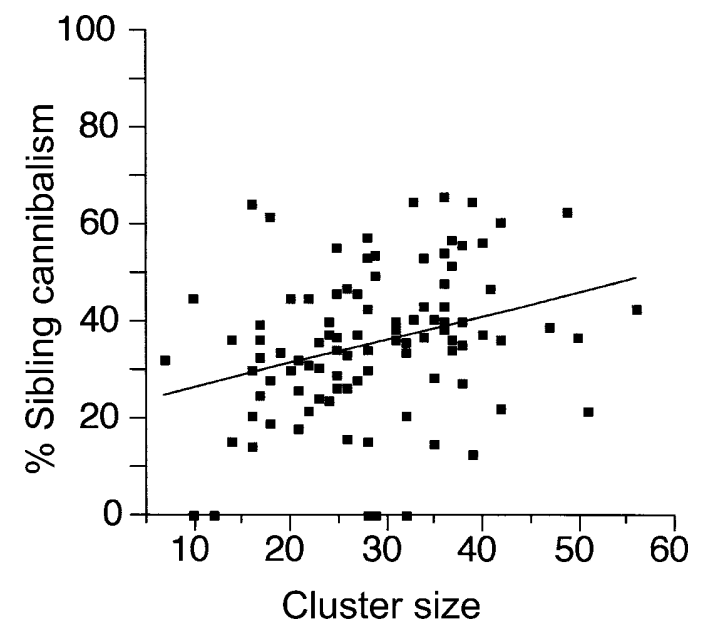

Fig. 2. The relationship between cluster size and the percentage of sibling cannibalism per cluster in the field experiment. The percentages were arcsine transformed.

\section{Field experiments}

Cluster size and the direct distance from a cluster site to the nearest aphid colony were significant factors affecting the number of cannibalized eggs per cluster when other factors (i.e., cluster site, the occurrence of aphid colonies on the same shoot, and the occurrence of aphid colonies on the same twig) were eliminated $(p<0.0001$, $p=0.0082$, respectively; $F_{4,96}=21.476, \mathrm{R}^{2}=0.472$, and $p$ $<0.0001$ for the model; Table 5). The effect of the route distance from a cluster site to the nearest aphid colony and the occurrence of clusters on the same shoot were not significant ( $p=0.0803, p=0.1712$, respectively; Table $5)$. Moreover, there was a weak but significant relationship between the percentage of sibling cannibalism per cluster and cluster size ( $F$-test: $F_{1,99}=10.765, \mathrm{R}^{2}=0.098$, and $p=0.0014$; Fig. 2). There was also a weak but significant relationship between cluster size and the direct distance from a cluster to the nearest aphid colony $(F$-test: $F_{1,99}=7.284, \mathrm{R}^{2}=0.069$, and $p=0.0082$; Fig. 3). How-

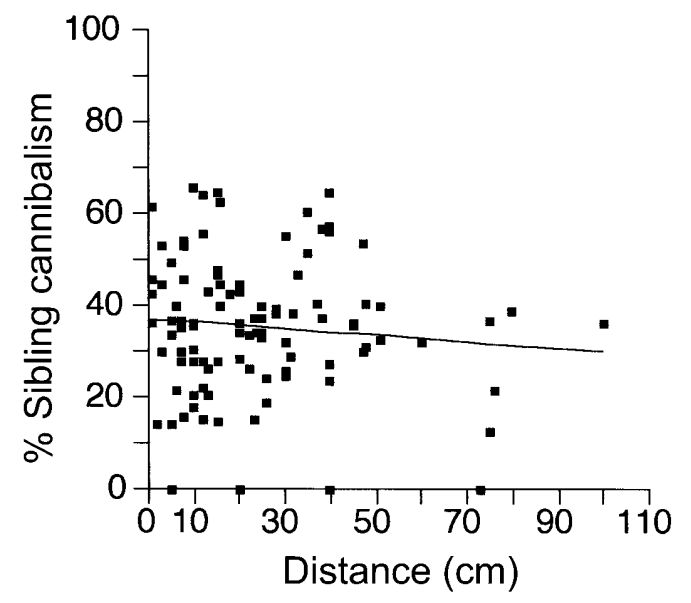

Fig. 4. The relationship between the direct distance $(\mathrm{cm})$ from a cluster site to the nearest aphid colony and the percentage of sibling cannibalism per cluster in the field experiment. The percentages were arcsine transformed.

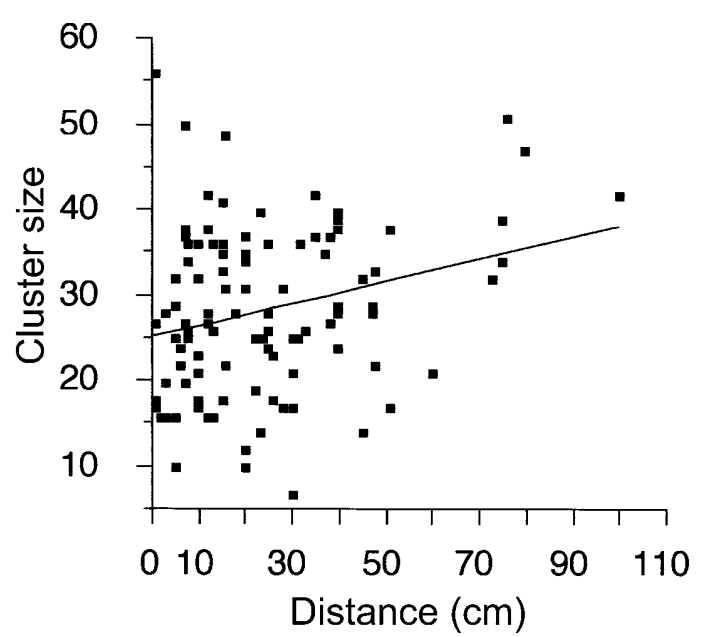

Fig. 3. The relationship between the direct distance $(\mathrm{cm})$ from a cluster site to the nearest aphid colony and cluster size in the field experiment.

ever, there was no significant relationship between the percentage of sibling cannibalism and the direct distance from a cluster to the nearest aphid colony ( $F$-test: $F_{1,99}=0.884$ and $p=0.349$; Fig. 4).

\section{DISCUSSION}

The results of this study showed that cluster size was clearly an important factor affecting both the number and the percentage of eggs cannibalized per cluster. Moreover, the field experiments indicated that there was a weak but significant relationship between cluster size and the direct distance from a cluster site to the nearest aphid colony. In the case of sibling cannibalism, a cannibal eats two types of eggs; infertile or fertile eggs dying at an early developmental stage, i.e. never-hatched eggs, and fertile eggs with delayed hatching. The existence of never-hatched eggs is regarded as direct maternal investment (i.e. the mother can control production of these directly) for the offspring, whereas that of fertile eggs with delayed hatching as indirect and/or fortuitous maternal investment (i.e. the mother does not control production of these directly) for females. Kawai (1978) reported sibling cannibalism in Harmonia axyridis was directed to $56 \%$ never-hatching and $44 \%$ of delayed hatching eggs, respectively. When a cannibal eats fertile eggs with delayed hatching, the differentiation in

TABLE 2. Two-way ANOVA of the number of cannibalised eggs per cluster $v s$. the occurrence of mating and cluster size in the laboratory experiment.

\begin{tabular}{lcrrr}
\hline Source & df & \multicolumn{1}{c}{ SS } & F-ratio & \multicolumn{1}{c}{$P$} \\
\hline Mating & 1 & 103.048 & 2.385 & 0.1256 \\
Cluster size & 1 & $3,896.663$ & 90.197 & $<0.0001$ \\
$\begin{array}{l}\text { Mating } \times \text { cluster } \\
\text { size }\end{array}$ & 1 & 119.607 & 2.769 & 0.0993 \\
Residual & 100 & $4,320.168$ & & \\
\hline
\end{tabular}

This is the remaining ANOVA model after stepwise removal of nonsignificant terms (oviposition interval, cluster size $\times$ oviposition interval, and oviposition interval $\times$ mating) at the oviposited shoot at the $\mathrm{P}<0.1$ level. 
TABLE 3. Two-way ANOVA of cluster size vs. the occurrence of mating and oviposition interval in the laboratory experiment.

\begin{tabular}{lcrrc}
\hline Source & df & \multicolumn{1}{c}{ SS } & F-ratio & $P$ \\
\hline Mating & 1 & 506.877 & 3.512 & 0.0639 \\
Oviposition interval* & 1 & $1,569.302$ & 10.872 & 0.0014 \\
$\begin{array}{l}\text { Mating×oviposition } \\
\text { interval }\end{array}$ & 1 & 266.177 & 1.844 & 0.1775 \\
Residual & 100 & $14,434.113$ & & \\
\hline
\end{tabular}

*oviposition interval was divided into two categories: short (= 1 day) and long ( $\geq 2$ days).

This is the remaining ANOVA model after stepwise removal of nonsignificant terms at the $\mathrm{P}<0.05$ level.

hatching time of each egg in a cluster may be important in determining the intensity of sibling cannibalism in a cluster. The laboratory and field experiments in this study showed that cluster size affected the percentage of sibling cannibalism per cluster. Therefore, hatching asynchrony in relation to cluster size may result in sibling cannibalism of fertile eggs with delayed hatching within a cluster. The percentage of sibling cannibalism per cluster should increase with the route distance if a female controls the proportion of never-hatched eggs per cluster with respect to the food availability for the offspring. This study showed that the route distance was not a significant factor affecting the percentage of sibling cannibalism per cluster. This suggests that females produce never-hatched eggs regardless of the food environment of the offspring Whereas, the direct distance was a significant factor affecting the percentage of sibling cannibalism per cluster, suggesting that escape from non-sibling cannibalism may be important in determining oviposition site

This study showed that cluster size increased with direct distance and the percentage of sibling cannibalism per cluster increased with cluster size. However, interestingly, the percentage sibling cannibalism per cluster did not increase with the direct distance. This difference was caused by a significant but weak relationship between cluster size and the direct distance $\left(\mathrm{R}^{2}=0.098\right)$, and

TABLE 5. Four-way ANOVA of the number of cannibalized eggs per cluster $v$ s. cluster size, the direct and route distance from a cluster site to the nearest aphid colony, and the occurrence of $H$. axyridis cluster on the same shoot in the field experiment.

\begin{tabular}{lcccc}
\hline Source & df & SS & F-ratio & $P$ \\
\hline Cluster size & 1 & $3,105.564$ & 79.586 & $<0.001$ \\
The direct distance & 1 & 284.169 & 7.282 & 0.0082 \\
The route distance & 1 & 121.892 & 3.124 & 0.0803 \\
$\begin{array}{l}\text { The occurrence of } H . \\
\text { axyridis }\end{array}$ & 1 & 74.156 & 1.9 & 0.1712 \\
$\begin{array}{l}\text { Clusters in the same } \\
\text { shoot }\end{array}$ & 1 & & & \\
Residual & 96 & $3,746.075$ & & \\
\hline
\end{tabular}

This is the remaining ANOVA model after stepwise removal of nonsignificant terms (cluster site, the occurrence of aphid colonies on the same shoot, and the occurrence of aphid colonies on the same twig) at the oviposition site at the $\mathrm{P}<0.05$ level.
Table 4. Two-level nested ANOVA of the percentage of sibling cannibalism per cluster $v s$. cluster size (female code) in the laboratory experiment.

\begin{tabular}{lcrcc}
\hline Source & df & \multicolumn{1}{c}{ SS } & F-ratio & $P$ \\
\hline Female code & 9 & $10,039.153$ & 3.606 & 0.0008 \\
$\begin{array}{l}\text { Cluster size (female } \\
\text { code) }\end{array}$ & 10 & $5,960.805$ & 1.927 & 0.0525 \\
Residual & 84 & $25,987.629$ & & \\
\hline
\end{tabular}

between the percentage of sibling cannibalism per cluster and cluster size $\left(\mathrm{R}^{2}=0.069\right)$. I suggest, therefore, that the female's power for controlling sibling cannibalism may be weak.

Dixon and Guo (1993) predicted that egg size is the least variable reproductive trait and that cluster size is the most variable. Cluster size in coccinellids is influenced by the nutritional status of the female (e.g., Dixon \& Guo, 1993). Furthermore, the average number of eggs laid in a cluster by a species is approximately half the number of ovarioles that a species has in its gonads when an individual is well fed (Stewart et al., 1991). However, I observed variation in cluster size in the laboratory, where food availability was constant. Furthermore, the percentage of sibling cannibalism of the same females also fluctuated in this study. In addition, cluster size and the number of cannibalized eggs per cluster in the long oviposition interval was significantly larger than those in the short one in this study. These results suggest that, in addition to food availability, the physiological condition of a female may affect cluster size.

The laboratory experiment showed that the occurrence of mating did not affect the number of cannibalized eggs per cluster. This may suggest that at least lack of sperm in fertilization does not affect the number of infertile eggs in a cluster, although a female without a male may have mated in the field before its collection for the experiment and the role of previous mating remains unknown.

By comparing several coccinellids species, Stewart et al. (1991) concluded that egg size is probably constrained by the minimum size at which first instar larvae can capture active prey and complete their development, before prey becomes scarce. However, newly hatched larvae cannot easily capture aphids (Dixon, 1959; Kawai, 1978) and they eat conspecific eggs preferentially (Kawai, 1978). These results indicate that egg size is insufficient for newly hatched larvae to become adults. Furthermore, Osawa (1989) suggested that in $H$. axyridis, female oviposition away from aphid colonies evolved under the pressure of intense predation near aphid colonies. The behaviour of the mother may well have evolved to maximise survival of the offspring given an unfavourable environment, with strong selection pressure for frequent sibling cannibalism.

It is known that $H$. axyridis has a large reproductive capacity (Soares et al., 2001). However, sibling cannibalism in coccinellids may be maladaptive when the mother lays eggs at a favorable oviposition site (i.e. a site with food quality and quantity guaranteed for larval development). In hoverflies, a mother assesses habitat 
quality using visual cues; a large proportion of winged aphids indicated that a colony would be short-lived and would consequently be an unsuitable oviposition site (Chandler, 1968; Kan \& Sasakawa, 1986). However, similar cues have not been identified for coccinellids. This study showed that cluster site, the occurrence of aphid colonies on the same shoot, the occurrence of aphid colonies on the same twig, the occurrence of egg clusters of $H$. axyridis on the same shoot, and the route distance from a cluster site to the nearest aphid colony were not significant factors affecting the percentage of sibling cannibalism per cluster. Furthermore, non-sibling cannibalism was more intense when egg clusters were close to an aphid colony (Osawa, 1989), indicating that intense non-sibling cannibalism can occur at suitable oviposition site for the offspring. These results suggest the female's assessment of future food availability for their offspring through sibling cannibalism controlling the ratio of neverhatched eggs per cluster may be extraordinarily difficult. Therefore, $H$. axyridis females control cluster size, mainly in response to the intensity of non-sibling cannibalism, and sibling cannibalism of eating fertile eggs with delayed hatching may occur in relation to cluster size, resulting in enhancement of the survival of the cannibal offspring under conditions of unpredictable and patchily distributed resources.

ACKNOWLEDGEMENTS. I am deeply grateful to the two anonymous referees for improving this manuscript. I am also much indebted to Prof. Emeritus E. Kuno, Laboratory of Entomology, Kyoto University, and Prof. H. Takeda, Laboratory of Forest Ecology, Kyoto University, who enabled me to conduct this study.

\section{REFERENCES}

AleXander R.D. 1974: The evolution of social behaviour. Anmu. Rev. Ecol. Syst. 4: 325-383.

Brown H.D. 1972: The behavior of newly hatched coccinellid larvae (Coleoptera: Coccinellidae). J. Entomol. Soc. S. Afr. 35: $149-157$.

ChANDLER A.E.F. 1968: The relationship between aphid infestations and oviposition by aphidophagous Syrphidae (Diptera). Ann. Appl. Biol. 61: 425-434.

DIXON A.F.G. 1959: An experimental study of the searching behavior of the predatory coccinellid beetle Adalia decempunctata (L.). J. Anim. Ecol. 28: 259-281.

Dixon A.F.G. \& Guro Y. 1993: Egg and cluster size in ladybird beetles (Coleoptera: Coccinellidae): The direct and indirect effects of aphid abundance. Eur. J. Entomol. 90: 457-463.

Dong Q. \& Polrs G.A. 1992: The dynamics of cannibalistic populations: a foraging perspective. In: Elgar M.K. \& Crespi B.J. (eds): Cannibalism: Ecology and Evolution among Diverse Taxa. Oxford University Press, New York, pp 13-37.

Doumbia M., Hemptinne J.-L. \& Dixon A.F.G. 1998: Assessment of patch quality by ladybirds: role of larval tracks. Oecologia 113: 197-202.

Evans E.W. \& Dixon A.F.G. 1986: Cues for oviposition by ladybird beetles (Coccinellidae): response to aphids. J. Anim. Ecol. 55: 1027-1034.

Fox L.R. 1975: Cannibalism in natural populations. Annu. Rev. Ecol. Syst. 6: 87-106.

GODFRY H.C.J. 1987: The evolution of clutch size in invertebrates. Oxf. Surv. Evol. Biol. 4: 117-154.
Hamilton W.D. 1964a: The genetical evolution of social behavior. I. J. Theor. Biol. 7: 1-16.

HAMILTON W.D. 1964b: The genetical evolution of social behavior. II. J. Theor. Biol. 7: 17-52.

Hemptinne J.-L., Dixon A.F.G. \& Coffin J. 1992: Attack strategy of ladybird beetles (Coccinellidae): factors shaping their numerical response. Oecologia 90: 238-245.

HODEK I. \& HoneK A. 1996: Ecology of Coccinellidae. Kluwer Acad. Publ., Dordrecht, 464 pp.

HONEK A. 1978: Trophic regulation of postdiapause ovariole maturation in Coccinella septempunctata (Col.: Coccinellidae). Entomophaga 23: 213-216.

HUrst G.D.D. \& MAJERUs M.E.N. 1993: Why do maternally inherited microorganisms kill males? Heredity 71: 81-95.

KANN E. \& SASAKaWa M. 1986: Assessment of maple aphid colony by the hoverfly, Episyrphus balteatus (de Geer) (Diptera: Syrphidae). J. Ethol. 4: 121-127.

KAWAI A. 1978: Sibling cannibalism in the first instar larvae of Harmonia axyridis Pallas (Coleoptera: Coccinelidae). Konty $\hat{u}$ 46: 14-19.

MiLLS N.J. 1982: Voracity, cannibalism and coccinellid predation. Ann. Appl. Biol. 101: 144-148.

OSAWA N. 1989: Sibling and non-sibling cannibalism by larvae of a lady beetle Harmonia axyridis Pallas (Coleoptera: Coccinelidae). Res. Popul. Ecol. 31: 153-160.

OSAWA N. 1992: Sibling cannibalism in the ladybird beetle Harmonia axyridis Pallas: fitness consequences for mother and offspring. Res. Popul. Ecol. 34: 45-55.

OSAWA N. 1993: Population field studies of the aphidophagous ladybird beetle Harmonia axyridis (Coleoptera: Coccinellidae): life tables and key factor analysis. Res. Popul. Ecol. 35: 335-348.

Osawa N. 2000: Population field studies on the aphidophagous ladybird beetle Harmonia axyridis (Coleoptera: Coccinellidae): resource tracking and population characteristics. Popul. Ecol. 42: 115-127.

Parker G.A. \& Courtney S.P. 1984: Models of clutch size in insect oviposition. Theor. Popul. Biol. 26: 27-48.

PoLis G.A. 1980: The effect of cannibalism on the demography and activity of a natural population of desert scorpions. Behav. Ecol. Sociobiol. 7: 25-35.

PoLIS G.A. 1981: The evolution and dynamics of intraspecific predation. Annu. Rev. Ecol. Syst. 12: 225-251.

SAS InSTITUTE 2000: JMP Statistical Discovery Software (ver. 4). SAS Institute Inc., Cary, NC.

SaSAII H. 1971: Fauna Japonica Coccinellidae. Academic Press of Japan, Tokyo, 340 pp.

SoAres A.O., Coderre D. \& Schanderl H. 2001: Fitness of two phenotypes of Harmonia axyridis (Coleoptera: Coccinellidae). Eur. J. Entomol. 98: 287-293.

Sokal R.R. \& Rohle F.J. 1980: Biometry Second Edition. W.H. Freeman, New York, $859 \mathrm{pp}$.

Stevens L. 1992: Cannibalism in beetles. In: Elgar M.K. \& Crespi B.J. (eds): Cannibalism: Ecology and Evolution among Diverse Taxa. Oxford University Press, New York, pp. 156-175.

Stewart L.A., Hemptinne J.-L. \& Dixon A.F.G. 1991: Reproductive tactics of ladybird beetles: relationships between egg size, ovariole number and developmetal time. Funct. Ecol. 5: 380-385.

WRATTEN S.D. 1973: The effectiveness of the coccinellid beetle, Adalia bipunctata (L.) as a predator of the lime aphid, Eucallipterus tiliae (L.). J. Anim. Ecol. 42: 785 p.

Received April 10, 2002; revised July 23, 2002; accepted November 25, 2002 